\title{
Craniotomy size for traumatic acute subdural hematomas in elderly patients-same procedure for every age?
}

\author{
Daniel Pinggera $^{1}$ ( $\cdot$ Marlies Bauer ${ }^{1} \cdot$ Michael Unterhofer $^{1} \cdot$ Claudius Thomé $^{1} \cdot$ Claudia Unterhofer $^{1}$
}

Received: 15 January 2021 / Revised: 25 March 2021 / Accepted: 12 April 2021 / Published online: 26 April 2021

(c) The Author(s) 2021

\begin{abstract}
Surgical treatment of acute subdural hematoma $(\mathrm{aSDH})$ is still matter of debate, especially in the elderly. A retrospective study to compare two different surgical approaches, namely standard (SC, craniotomy size $>8 \mathrm{~cm}$ ) and limited craniotomy (LC, craniotomy size $<8 \mathrm{~cm}$ ), was conducted in elderly patients with traumatic aSDH to identify the role of craniotomy size in terms of clinical and radiological outcome. Sixty-four patients aged 75 or older with aSDH as sole lesion were retrospectively analyzed. Data were collected pre- and postoperatively including clinical and radiological criteria. The primary outcome parameter was 30-day mortality. Secondary outcome parameters were radiological. The mean age was $79.2( \pm 3.1)$ years with no difference between groups and almost equal distribution of craniotomy size. Mortality rate was significantly higher in the SC group in comparison to the LC group (68.4\% vs. $31.6 \% ; p=0.045)$. The preoperative HD $(p=0.08)$ and the MLS $(p=0.09)$ were significantly higher in the SC group, whereas postoperative radiological evaluation showed no significant difference in HD or MLS. A limited craniotomy is sufficient for adequate evacuation of an aSDH in the elderly achieving the same radiological and clinical outcome.
\end{abstract}

Keywords Acute subdural hematoma $\cdot$ Elderly $\cdot$ Outcome $\cdot$ Surgical technique

\section{Introduction}

Population aging will lead to a rising number of traumatic brain injuries (TBI) in the eldery, causing major public health and socioeconomic problems [29]. Ten to $20 \%$ of TBI patients present with an acute subdural hematoma (aSDH) and the incidence in very old patients has increased over the recent years $[14,37]$. The mortality from aSDH in old patients remains high, reaching 40 to $60 \%$, and only 19 to $45 \%$ are reported to gain functional recovery $[19,20]$. Age over 65 years is associated with poor outcome in many studies and mortality exceedingly rises, if the patient is older than 70 and presents with a GCS score of 9 or less [4, 12, $23,36]$. For aSDH, surgical management was not shown to be an effective treatment in elderly patients with a GCS of 3 to 5 [28].

The current body of literature mainly focuses on younger patients below the age of 65 years, causing low evidence if

Daniel Pinggera

daniel.pinggera@tirol-kliniken.at

1 Department of Neurosurgery, Medical University Innsbruck, Anichstrasse 35, 6020 Innsbruck, Austria and how to perform surgery in elderly patients $[6,21,26]$. Surgical treatment of choice for aSDH includes hematoma evacuation via craniotomy or decompressive craniectomy $[2,18,27]$. Parameters to be considered for choosing the surgical approach include, inter alia: radiological parameters, preoperative neurologic status, and associated intracerebral hemorrhage [5, 33]. Lower GCS, greater hematoma thickness, or midline shift correlate with poorer outcome, whereas patients treated with decompressive craniectomy (DC) show either equal or worse outcome $[5,8,14,17,20$, 22].

Therefore, operative management of aSDH in the elderly population is a controversial topic, with no treatment guidelines on hand. In older patients, decompressive craniectomy does not show significant benefit after failing maximal medical treatment. One year after decompressive craniectomy, $80 \%$ of elderly patients with severe TBI had poor outcome [24]. For all these reasons, clinical decision-making in old patients with aSDH is cumbersome with a heterogenous approach among neurosurgeons as described elsewhere [17, $31,32]$. Besides the decision if to perform surgery at all, the extent of the surgical approach is also a matter of debate, as DC is often associated with serious complications like 
extraaxial fluid collection, skin-flap-associated subcutaneous hematoma, or external brain herniation [10]. Also, surgical approach and operation time ought to be kept at a minimum to reduce perioperative and postoperative complications [30].

In the present study, we therefore analyzed the influence of craniotomy size on clinical (mortality) and radiological (postoperative hematoma depth and midline shift) criteria. We refer to Jiang et al., who proposes a cut-off value of $80 \mathrm{~mm}$ to differentiate between standard (SC, $>80 \mathrm{~mm})$ and limited craniotomy (LC, $<80 \mathrm{~mm}$ ) [13].

\section{Materials and methods}

All patients aged above 75 years with TBI, who presented to our Department between 01/2000 and 12/2019, were retrospectively reviewed. Of those, only surgically treated patients with isolated aSDH were included in the final analysis. Exclusion criteria were non-traumatic aSDH, subacute/ chronic subdural hematoma, further intracranial lesions (epidural hematoma, intracerebral hematoma), or unavailable medical records.

From a total of 564 patients presenting with TBI, 64 patients met the inclusion criteria and were analyzed. All patients were treated in accordance with the Declaration of Helsinki and Austrian regulations. Demographic and clinical data were collected from medical data records including patient age, sex, initial GCS, surgical procedure (standard "large" craniotomy or limited "small" craniotomy), type of trauma (high or low impact trauma), and mortality after 30 days. In addition, presence of anticoagulant or anti-platelet therapy on admission and comorbidities (hypertension, cardiovascular diseases, malignomas) were analyzed. Standard craniotomy (SC) was defined as a frontotemporoparietal craniotomy $(>8 \mathrm{~cm})$ opposed to a temporoparietal craniotomy ( $<8 \mathrm{~cm}$, limited craniotomy, LC).

Radiographic parameters collected pre- and postoperatively were hematoma depth (HD) and midline shift (MLS). Hematoma depth was measured in millimeters in the axial plane starting from the inner table of the skull to the innermost boundary of the hematoma. The extent of midline shift in millimeters (MS) was measured also in the axial plane as the perpendicular distance between the septum pellucidum and a line indicating the midline of the skull. Additionally, the maximum anterioposterior length of the bone flap was measured in millimeters on postoperative axial CT scans. Radiological data was gathered from initial CT scans. If a patient was referred from a peripheral hospital, initial imaging was used when available.

To reduce selection bias based on GCS, a subanalysis was conducted in which patients with a GCS of 3 were excluded in the SC group and patients with a GCS of 15 in the LC group, accordingly.

Imaging data were analyzed using Icoserve Advanced Imaging Management (V.1.8.8.34, ITH Icoserve Technology for Healthcare $\mathrm{GmbH}$, Innsbruck, Austria).

Statistical analyses were conducted using IBM SPSS Statistics 24 (IBM Corporation, Armonk, NY, USA). Differences with a $p$-value of less than 0.05 were considered statistically significant. In the univariate analysis, group differences were determined using the chi-square test for dichotomized variables. Continuous variables were analyzed using the independent samples $t$-test and the Mann-Whitney $U$-test, as appropriate. Receiver-operating characteristics analysis was used to calculate the cut-off value for craniotomy size in our series. Multivariate analysis was performed to identify predictive parameters for mortality.

The study was approved by the local ethics committee of the Medical University Innsbruck (Protocol number: AN2020-1115/2020). Due to its retrospective nature and the fact that the study relied on information obtained as part of routine clinical practice, no informed consent was needed.

\section{Results}

\section{Patient characteristics}

In this retrospective study, a total of 64 patients aged above 75 years presenting with an aSDH and requiring surgery were evaluated. Thirty-six (56.3\%) were male and 28 (43.7\%) were female. The mean age at surgery was 79.2 , with age ranging from 75 to 85 years. Mean GCS at admission was 11 (range 3-15). Fifty-four patients (84.4\%) received some form of antithrombotic therapy prior to trauma. The remaining patients' anticoagulation status was either unknown or no record of prior medication was available.

Fifty patients (78.1\%) suffered from a low-impact trauma, 14 patients $(21.9 \%)$ from a high-impact injury.

Hypertension was seen in $46.9 \%$ ( $n=30$ patients), cardiovascular diseases in $70.3 \%$ ( $n=30$ patients), and history of malignoma in $12.5 \%(n=8)$. Comorbidities did not significantly differ when grouped according to the size of bone flap, but a trend is seen towards sicker patients in the group treated with a limited craniotomy $(<\mathrm{LC} ; 80 \mathrm{~mm})$ (Table 1$)$.

\section{Radiological data and surgical approach}

Mean hematoma depth preoperatively amounted to $17.2 \mathrm{~mm}$ (range $8-32 \mathrm{~mm}$ ), and mean midline shift was $12.1 \mathrm{~mm}$, ranging from 0 to $30 \mathrm{~mm}$. Two patients presented with a hematoma depth below $10 \mathrm{~mm}$ but were treated surgically due to present midline shift and severe neurological 
Table 1 Group comparison of limited versus standard craniotomy (ns: not significant)

\begin{tabular}{llll}
\hline & $\begin{array}{l}\text { Limited craniotomy } \\
(\mathrm{LC},<80 \mathrm{~mm})\end{array}$ & $\begin{array}{l}\text { Standard craniot- } \\
\text { omy (SC, > 80 mm) }\end{array}$ & \\
\hline Number of patients & 34 & 30 & $\mathrm{~ns}$ \\
Age (mean) & 78.7 & 79.6 & $\mathrm{~ns}$ \\
Female (\%) & $50 \%$ & $37 \%$ & $p=0.013$ \\
GCS (mean) & 12 & 7 & $p=<0.01$ \\
Size of bone flap (mean) & $52.7 \mathrm{~mm}$ & $108.6 \mathrm{~mm}$ & $p=0.04$ \\
Hematoma depth preoperatively (mean) & $15.2 \mathrm{~mm}$ & $19.4 \mathrm{~mm}$ & $p<0.01$ \\
Midline shift preoperatively (mean) & $9.9 \mathrm{~mm}$ & $14.7 \mathrm{~mm}$ & $\mathrm{~ns}$ \\
Hematoma depth postoperatively (mean) & $4.8 \mathrm{~mm}$ & $6.2 \mathrm{~mm}$ & $\mathrm{~ns}$ \\
Midline shift postoperatively (mean) & $4.4 \mathrm{~mm}$ & $4.7 \mathrm{~mm}$ & $\mathrm{~ns}$ \\
Hypertension & $32.8 \%$ & $14.1 \%$ & $\mathrm{~ns}$ \\
Cardiovascular diseases & $43.8 \%$ & $26.6 \%$ & $\mathrm{~ns}$ \\
Malignomas & $7.8 \%$ & $4.7 \%$ & $\mathrm{~ns}$ \\
Percentage reduction of hematoma depth (mean) & $71.5 \%$ & $63.4 \%$ & $\mathrm{~ns}$ \\
Percentage reduction of midline shift (mean) & $56.1 \%$ & $54.2 \%$ & $p=0.045$ \\
Mortality within 30 days & $23.1 \%$ & $52.0 \%$ &
\end{tabular}

symptoms. Measurement of radiological parameters postoperatively showed a mean residual hematoma depth of $5.5 \mathrm{~mm}$ (range 0-21 mm) and a mean residual midline shift of $4.5 \mathrm{~mm}$ (ranging 0-13 $\mathrm{mm}$ ).

Mean size of the bone flap was $78.9 \mathrm{~mm}$, ranging from 27 to $161 \mathrm{~mm}$. For better comparison to the literature, a cut-off value of $80 \mathrm{~mm}$ was defined [13].

Grouped according to the size of bone flap, 30 patients $(47 \%)$ were treated with a limited craniotomy $(<\mathrm{LC} ; 80 \mathrm{~mm})$ and 34 patients $(53 \%)$ with a standard craniotomy ( $\mathrm{SC} ;>80 \mathrm{~mm})$. This resulted in an average flap size of approximately $5 \mathrm{~cm}$ in the LC group and of approximately $11 \mathrm{~cm}$ in the SC group (Table 1 and Fig. 1).

Twelve SC patients (18\%) received a decompressive craniectomy defined as an extensive craniotomy with the bone flap left out. Age and gender were distributed equally among groups, same as postoperative hematoma depth and midline shift. Preoperative depth of hematoma and midline shift were significantly higher in the SC group, whereas GCS was significantly lower in this group.

Logistic regression analysis was created using the following variables: GCS, size of bone flap, hematoma depth, and midline shift. The model was then optimized using backward stepwise conditional elimination. In the resulting model, none of the parameters showed statistical significance.

\section{Outcome}

Outcome was analyzed as trauma-related mortality within 30 days, which accounted to $36 \%$ (18 patients) overall. There was a significantly higher mortality in the SC group with no benefits in regard to radiological parameters. None of the patients had to undergo second surgery for residual hematoma (Table 1). Within the $S C$ group, 2 patients with decompressive craniectomy died within 30 days.

\section{Subanalysis}

Excluding patients with a GCS of 3 in the SC group and patients with a GCS of 15 in the LC group led to a more homogeneous distribution of GCS between groups with a

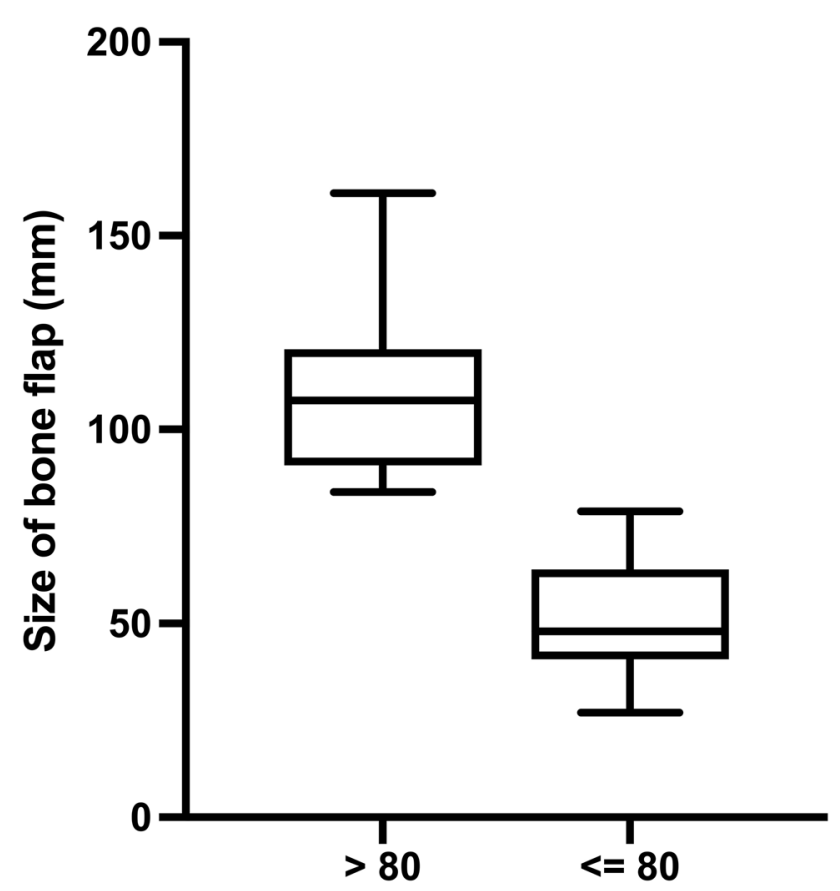

Fig. 1 Distribution of size of bone flap between LC and SC (median + IQR) 
mean of 10 (SC group; $n=21$ ) and 12 (LC group; $n=25$ ), respectively. Mortality was comparable at $25 \%$ and $30 \%$ and no other parameter showed a statistically significant difference (Table 2).

\section{Discussion}

While evacuation of aSDH in the general trauma population is usually performed via an extensive craniotomy or decompressive craniectomy more than $10 \mathrm{~cm}$ in size, a small craniotomy may suffice in elderly patients. The results of this first study investigating the influence of craniotomy size in patients aged above 75 years with aSDH demonstrate that a craniotomy sized $80 \mathrm{~mm}$ or less may achieve a sufficient radiological result with small residual hematoma depth and MLS not requiring revision surgery.

Despite an aging population with a consecutively rising number of TBIs, sufficient data and treatment guidelines are lacking [29]. Therefore, the choice of the surgical procedure in elderly patients is still based on data generated in younger patients or on the surgeon's expertise. Important factors influencing indication for surgery in the elderly include age, midline shift, hematoma thickness, and presence of anticoagulation therapy [31]. Interestingly, in patients on oral anticoagulation medication and aged above 80 years, those radiological parameters do not seem to influence outcome and an oral anticoagulant therapy regimen is exceedingly common as seen in our data $(84 \%)$ and the literature $[37,38]$. This also comes in hand with an increasing number of patients presenting with delayed neurological deterioration. Minor traumatic events in elderly patients on anticoagulant therapy can easily cause aSDH, resulting in a delayed appearance of symptoms with initial unremarkable neurological status $[2,14]$. Given the results of an online questionary, almost half of neurosurgeons choose a large osteoplastic craniotomy when performing surgery, in contrast to $13 \%$ considering a small osteoplastic craniotomy or $28 \%$ performing a decompressive craniectomy [31]. The latter comes with drawbacks including subdural effusion, leakage of cerebrospinal fluid, or external herniation $[9,10]$. However, there is a paucity of evidence in the literature regarding the best surgical strategy for aSDH for the elderly and surgical decision-making is often haphazard. Additionally, the discussion of craniotomy versus decompressive craniectomy is still controversial, same as the size of craniotomy $[15,27,34]$. Data obtained in the prospective RESCUE-ASDH trial are long-awaited [16].

In the elderly, neurosurgeons try to achieve a balance between largest craniotomy possible, while avoiding concurrent drawbacks of decompressive craniectomy [7, 18]. A small series of 44 patients aged above 75 described a low mortality, when patients were conscious and without antithrombotic medication prior to surgery [25]. The type of surgery, however, was not reported. Similar to our results, another series of 62 patients aged above 65 years found a mortality of $37 \%$ [1]. Most of the patients $(86 \%)$ were treated with a craniotomy. In addition to the younger age, midline shift was higher and patients with intracerebral contusions were included as well, making comparison difficult [1]. Corresponding to our findings, no significant differences in hematoma depth and midline shift pre- and postoperatively in respect to outcome in a cohort mainly treated with craniotomy were reported [3]. Yet, no further details about the size of the craniotomies are presented, neither is elsewhere in the literature. As no second surgery or re-operation had to be performed in our series, we conclude that there is little risk for secondary brain swelling in this population. Also, in the overall and selective analysis, a LC with an average flap size of approximately $5 \mathrm{~cm}$ shows comparable postoperative radiological and clinical outcome.

Age and low GCS are still the major determinants of outcome after brain injury with increasing mortality with
Table 2 Group comparison limited versus standard craniotomy in the selected analysis, excluding patients with a GCS of 3 in the SC group and GCS of 15 in the LC group (ns: not significant)

\begin{tabular}{llll}
\hline & $\begin{array}{l}\text { Limited craniotomy } \\
(\mathrm{LC},<80 \mathrm{~mm})\end{array}$ & $\begin{array}{l}\text { Standard craniot- } \\
\text { omy (SC, }>80 \mathrm{~mm})\end{array}$ \\
\hline Number of patients & 25 & 21 & \\
Age (mean) & 79.2 & 79.5 & $\mathrm{~ns}$ \\
Female (\%) & $56 \%$ & $47 \%$ & $\mathrm{~ns}$ \\
GCS (mean) & 10 & 12 & $\mathrm{~ns}$ \\
Size of bone flap (mean) & $52.6 \mathrm{~mm}$ & $104.4 \mathrm{~mm}$ & $p=<0.01$ \\
Hematoma depth preoperatively (mean) & $15.3 \mathrm{~mm}$ & $18.4 \mathrm{~mm}$ & $\mathrm{~ns}$ \\
Midline shift preoperatively (mean) & $9.8 \mathrm{~mm}$ & $13.6 \mathrm{~mm}$ & $\mathrm{~ns}$ \\
Hematoma depth postoperatively (mean) & $5.1 \mathrm{~mm}$ & $6.8 \mathrm{~mm}$ & $\mathrm{~ns}$ \\
Midline shift postoperatively (mean) & $3.9 \mathrm{~mm}$ & $4.2 \mathrm{~mm}$ & $\mathrm{~ns}$ \\
Percentage reduction of hematoma depth (mean) & $77.3 \%$ & $64.5 \%$ & $\mathrm{~ns}$ \\
Percentage reduction of midline shift (mean) & $59.9 \%$ & $59.8 \%$ & $\mathrm{~ns}$ \\
Mortality within 30 days & $25.0 \%$ & $30.0 \%$ & $\mathrm{~ns}$ \\
\hline
\end{tabular}


higher age $[3,28,35]$. Very old patients with an initial GCS of 3-5 have an unfavorable outcome and higher mortality as compared to those with a GCS of 6-15 [25, 28]. In addition, patients aged above 80 years will die in 50\% after critical illness with only one-fourth recovering to pre-hospital function [11]. Still, tendencies to perform surgery are high, even in the elderly [1, 25, 28, 37]. Also in our study, patients with a low GCS and SC or DC showed a high mortality rate in univariate analysis, but not in multivariate analysis. A possible explanation may be found in the sample size and the collinearity of the radiological parameters. The subanalysis after excluding the very poor and the very good patients investigated comparable patients according to their initial GCS. In these 44 patients ( 20 vs. 24 ), a small " $5 \mathrm{~cm}$ " craniotomy allowed a sufficient hematoma evacuation.

Our study is within the range of mortality rates reported in the literature for surgical evacuation of aSDH in the elderly population. Studies that had an even older age as inclusion criterion reported worse mortality rates, except for Won et al., who found an initial $27 \%$ mortality rate in patients over 80 years of age who underwent surgical evacuation for aSDH [37]. The type of surgery, however, was not mentioned. All in common are little case numbers, hampering comparison [3].

Several limitations need to be acknowledged in our study, being retrospective the most obvious one. Furthermore, our cohort probably represents a selection of patients who were judged to have good chances of favorable outcome by the attending neurosurgeons and therefore received surgery. Additionally, clinical outcome was assessed as mortality within 30 days, excluding patients dying thereafter. Last, group allocation was based on the decision of the attending surgeon and not on random allocation.

In summary, patients aged 75 years or above with aSDH do not seem to be at risk for postoperative brain swelling and hematoma evacuation can be achieved via a small craniotomy. This may minimize surgical trauma, and reduce operative time and wound complications. Further studies should be performed to confirm our results. It needs to be kept in mind that the vast majority of patients receive anticoagulative or antiaggregative medication.

\section{Conclusions}

Neurosurgeons tend to apply larger craniotomies for aSDH even in the elderly in case of low GCS and large HD and MLS. Limited craniotomies with an average size of $5 \mathrm{~cm}$, however, seem to be sufficient and feasible in patients aged above 75 years to evacuate aSDH, achieving comparable surgical decompression.
Author contribution Study design was made by Claudia Unterhofer. Data collection and analysis were performed by Claudia Unterhofer, Michael Unterhofer, Marlies Bauer, and Daniel Pinggera. The first draft of the manuscript was written by Daniel Pinggera and all authors commented on previous versions of the manuscript. Claudius Thomé made a substantial contribution to revising the original draft. All authors read and approved the final manuscript.

Funding Open access funding provided by University of Innsbruck and Medical University of Innsbruck.

Data availability Data transparency was confirmed.

Code availability Not applicable.

\section{Declarations}

Ethics approval The study was approved by the local ethics committee of the Medical University Innsbruck (Protocol number: AN2020$1115 / 2020$ ).

Consent to participate Due to its retrospective nature and the fact that the study relied on information obtained as part of routine clinical practice, no informed consent was needed.

Consent for publication Not applicable.

Conflict of interest The authors declare no competing interests.

Open Access This article is licensed under a Creative Commons Attribution 4.0 International License, which permits use, sharing, adaptation, distribution and reproduction in any medium or format, as long as you give appropriate credit to the original author(s) and the source, provide a link to the Creative Commons licence, and indicate if changes were made. The images or other third party material in this article are included in the article's Creative Commons licence, unless indicated otherwise in a credit line to the material. If material is not included in the article's Creative Commons licence and your intended use is not permitted by statutory regulation or exceeds the permitted use, you will need to obtain permission directly from the copyright holder. To view a copy of this licence, visit http://creativecommons.org/licenses/by/4.0/.

\section{References}

1. Akbik OS, Starling RV, Gahramanov S, Zhu Y, Lewis J (2019) Mortality and functional outcome in surgically evacuated scute subdural hematoma in elderly patients. World Neurosurg 126:e1235-e1241. https://doi.org/10.1016/j.wneu.2019.02.234

2. Bullock MR, Chesnut R, Ghajar J, Gordon D, Hartl R, Newell DW, Servadei F, Walters BC, Wilberger JE (2006) Guidelines for the surgical management of traumatic brain injury author group. Neurosurgery 58:S2-1-S2-3. https://doi.org/10.1227/01.neu. 0000210361.83548.d0

3. Bus S, Verbaan D, Kerklaan BJ, Sprengers MES, Vandertop WP, Stam J, Bouma GJ, van den Munckhof P (2019) Do older patients with acute or subacute subdural hematoma benefit from surgery? Br J Neurosurg 33:51-57. https://doi.org/10.1080/02688697.2018. 1522418

4. Cagetti B, Cossu M, Pau A, Rivano C, Viale G (1992) The outcome from acute subdural and epidural intracranial haematomas 
in very elderly patients. Br J Neurosurg 6:227-231. https://doi. org/10.3109/02688699209002930

5. Chen SH, Chen Y, Fang WK, Huang DW, Huang KC, Tseng SH (2011) Comparison of craniotomy and decompressive craniectomy in severely head-injured patients with acute subdural hematoma. J Trauma 71:1632-1636. https://doi.org/10.1097/TA.0b013 e3182367b3c

6. Collaborators MCT, Perel P, Arango M, Clayton T, Edwards P, Komolafe E, Poccock S, Roberts I, Shakur H, Steyerberg E, Yutthakasemsunt S (2008) Predicting outcome after traumatic brain injury: practical prognostic models based on large cohort of international patients. BMJ 336:425-429. https://doi.org/10.1136/bmj. 39461.643438 .25

7. De Bonis P, Pompucci A, Mangiola A, Paternoster G, Festa R, Nucci CG, Maviglia R, Antonelli M, Anile C (2011) Decompressive craniectomy for elderly patients with traumatic brain injury: it's probably not worth the while. J Neurotrauma 28:2043-2048. https://doi.org/10.1089/neu.2011.1889

8. Fountain DM, Kolias AG, Lecky FE, Bouamra O, Lawrence T, Adams H, Bond SJ, Hutchinson PJ (2017) Survival trends after surgery for acute subdural hematoma in adults over a 20-year period. Ann Surg 265:590-596. https://doi.org/10.1097/SLA. 0000000000001682

9. Gopalakrishnan MS, Shanbhag NC, Shukla DP, Konar SK, Bhat DI, Devi BI (2018) Complications of decompressive craniectomy. Front Neurol 9:977. https://doi.org/10.3389/fneur.2018.00977

10. Hanko M, Sorsak J, Snopko P, Opsenak R, Zelenak K, Kolarovszki B (2020) Incidence and risk factors of early postoperative complications in patients after decompressive craniectomy: a 5-year experience. Eur J Trauma Emerg Surg. https://doi.org/10. 1007/s00068-020-01367-4

11. Heyland DK, Garland A, Bagshaw SM, Cook D, Rockwood K, Stelfox HT, Dodek P, Fowler RA, Turgeon AF, Burns K, Muscedere J, Kutsogiannis J, Albert M, Mehta S, Jiang X, Day AG (2015) Recovery after critical illness in patients aged 80 years or older: a multi-center prospective observational cohort study. Intensive Care Med 41:1911-1920. https://doi.org/10.1007/ s00134-015-4028-2

12. Jamjoom A (1992) Justification for evacuating acute subdural haematomas in patients above the age of 75 years. Injury 23:518-520. https://doi.org/10.1016/0020-1383(92)90149-m

13. Jiang JY, Xu W, Li WP, Xu WH, Zhang J, Bao YH, Ying YH, Luo QZ (2005) Efficacy of standard trauma craniectomy for refractory intracranial hypertension with severe traumatic brain injury: a multicenter, prospective, randomized controlled study. J Neurotrauma 22:623-628. https://doi.org/10.1089/neu.2005.22.623

14. Karibe HHT, Hirano T, Kameyama M, Nakagawa A, Tominaga $\mathrm{T}$ (2014) Surgical managment of traumatic acute subdural hematoma in adults: a review. Neurol Med Chir. https://doi.org/10. 2176/nmc.ra.2014-0204

15. Kim H, Suh SJ, Kang HJ, Lee MS, Lee YS, Lee JH, Kang DG (2018) Predictable values of decompressive craniectomy in patients with acute subdural hematoma: comparison between decompressive craniectomy after craniotomy group and craniotomy only group. Korean J Neurotrauma 14:14-19. https://doi. org/10.13004/kjnt.2018.14.1.14

16. Kolias AG, Adams H, Timofeev I, Czosnyka M, Corteen EA, Pickard JD, Turner C, Gregson BA, Kirkpatrick PJ, Murray GD, Menon DK, Hutchinson PJ (2016) Decompressive craniectomy following traumatic brain injury: developing the evidence base. Br J Neurosurg 30:246-250. https://doi.org/10.3109/02688697. 2016.1159655

17. Kolias AG, Scotton WJ, Belli A, King AT, Brennan PM, Bulters DO, Eljamel MS, Wilson MH, Papadopoulos MC, Mendelow AD, Menon DK, Hutchinson PJ, Network UKNR, group R-Ac,
(2013) Surgical management of acute subdural haematomas: current practice patterns in the United Kingdom and the Republic of Ireland. Br J Neurosurg 27:330-333. https://doi.org/10.3109/ 02688697.2013.779365

18. Kwon YS, Yang KH, Lee YH (2016) Craniotomy or decompressive craniectomy for acute subdural hematomas: surgical selection and clinical outcome. Korean J Neurotrauma 12:22-27. https:// doi.org/10.13004/kjnt.2016.12.1.22

19. Leitgeb J, Mauritz W, Brazinova A, Janciak I, Majdan M, Wilbacher I, Rusnak M (2012) Outcome after severe brain trauma due to acute subdural hematoma. J Neurosurg 117:324-333. https:// doi.org/10.3171/2012.4.JNS111448

20. Li LM, Kolias AG, Guilfoyle MR, Timofeev I, Corteen EA, Pickard JD, Menon DK, Kirkpatrick PJ, Hutchinson PJ (2012) Outcome following evacuation of acute subdural haematomas: a comparison of craniotomy with decompressive craniectomy. Acta Neurochir 154:1555-1561. https://doi.org/10.1007/ s00701-012-1428-8

21. Maas AI, Marmarou A, Murray GD, Teasdale SG, Steyerberg EW (2007) Prognosis and clinical trial design in traumatic brain injury: the IMPACT study. J Neurotrauma 24:232-238. https:// doi.org/10.1089/neu.2006.0024

22. Oh CH, Shim YS, Yoon SH, Hyun D, Park H, Kim E (2016) Early decompression of acute subdural hematoma for postoperative neurological improvement: a single center retrospective review of 10 years. Korean J Neurotrauma 12:11-17. https://doi.org/10.13004/ kjnt.2016.12.1.11

23. Peeters W, van den Brande R, Polinder S, Brazinova A, Steyerberg EW, Lingsma HF, Maas AI (2015) Epidemiology of traumatic brain injury in Europe. Acta Neurochir 157:1683-1696. https:// doi.org/10.1007/s00701-015-2512-7

24. Pompucci A, De Bonis P, Pettorini B, Petrella G, Di Chirico A, Anile C (2007) Decompressive craniectomy for traumatic brain injury: patient age and outcome. J Neurotrauma 24:1182-1188. https://doi.org/10.1089/neu.2006.0244

25. Raj R, Mikkonen ED, Kivisaari R, Skrifvars MB, Korja M, Siironen J (2016) Mortality in elderly patients operated for an acute subdural hematoma: a surgical case series. World Neurosurg 88:592-597. https://doi.org/10.1016/j.wneu.2015.10.095

26. Roozenbeek B, Maas AI, Marmarou A, Butcher I, Lingsma HF, Lu J, McHugh GS, Murray GD, Steyerberg EW, Group IS (2009) The influence of enrollment criteria on recruitment and outcome distribution in traumatic brain injury studies: results from the impact study. J Neurotrauma 26:1069-1075. https://doi.org/10. 1089/neu.2008.0569

27. Rush B, Rousseau J, Sekhon MS, Griesdale DE (2016) Craniotomy versus craniectomy for acute traumatic subdural hematoma in the United States: a national retrospective cohort analysis. World Neurosurg 88:25-31. https://doi.org/10.1016/j.wneu.2015.12.034

28. Shimoda K, Maeda T, Tado M, Yoshino A, Katayama Y, Bullock MR (2014) Outcome and surgical management for geriatric traumatic brain injury: analysis of 888 cases registered in the Japan Neurotrauma Data Bank. World Neurosurg 82:1300-1306. https:// doi.org/10.1016/j.wneu.2014.08.014

29. Tagliaferri F, Compagnone C, Korsic M, Servadei F, Kraus J (2006) A systematic review of brain injury epidemiology in Europe. Acta Neurochirurgica 148:255-268; discussion 268. https://doi.org/10.1007/s00701-005-0651-y

30. Turrentine FE, Wang H, Simpson VB, Jones RS (2006) Surgical risk factors, morbidity, and mortality in elderly patients. J Am Coll Surg 203:865-877. https://doi.org/10.1016/j.jamcollsurg. 2006.08.026

31. Unterhofer C, Hartmann S, Freyschlag CF, Thome C, Ortler M (2018) Severe head injury in very old patients: to treat or not to treat? Results of an online questionnaire for neurosurgeons. 
Neurosurg Rev 41:183-187. https://doi.org/10.1007/ s10143-017-0833-0

32. Unterhofer C, Ho WM, Wittlinger K, Thome C, Ortler M (2017) "I am not afraid of death"-a survey on preferences concerning neurosurgical interventions among patients over 75 years. Acta Neurochir 159:1547-1552. https://doi.org/10.1007/s00701-017-3240-y

33. van Essen TA, de Ruiter GC, Kho KH, Peul WC (2017) Neurosurgical treatment variation of traumatic brain injury: evaluation of acute subdural hematoma management in Belgium and The Netherlands. J Neurotrauma 34:881-889. https://doi.org/10.1089/ neu.2016.4495

34. Vilcinis R, Bunevicius A, Tamasauskas A (2017) The association of surgical method with outcomes of acute subdural hematoma patients: experience with 643 consecutive patients. World Neurosurg 101:335-342. https://doi.org/10.1016/j.wneu.2017.02.010

35. Wilberger JE Jr, Harris M, Diamond DL (1990) Acute subdural hematoma: morbidity and mortality related to timing of operative intervention. J Trauma 30:733-736

36. Wilberger JE Jr, Harris M, Diamond DL (1991) Acute subdural hematoma: morbidity, mortality, and operative timing. J
Neurosurg 74:212-218. https://doi.org/10.3171/jns.1991.74.2. 0212

37. Won SY, Dubinski D, Brawanski N, Strzelczyk A, Seifert V, Freiman TM, Konczalla J (2017) Significant increase in acute subdural hematoma in octo- and nonagenarians: surgical treatment, functional outcome, and predictors in this patient cohort. Neurosurg Focus 43:E10. https://doi.org/10.3171/2017.7.FOCUS 17417

38. Won SY, Dubinski D, Bruder M, Cattani A, Seifert V, Konczalla J (2017) Acute subdural hematoma in patients on oral anticoagulant therapy: management and outcome. Neurosurg Focus 43:E12. https://doi.org/10.3171/2017.8.FOCUS17421

Publisher's note Springer Nature remains neutral with regard to jurisdictional claims in published maps and institutional affiliations. 